\title{
The Epigenetic Impact of Cruciferous Vegetables on Cancer Prevention
}

\author{
Kendra J. Royston • Trygve O. Tollefsbol
}

Published online: 25 January 2015

(C) Springer International Publishing AG 2015

\begin{abstract}
The answer to chemoprevention has perhaps been available to the general public since the dawn of time. The epigenetic diet is of extreme interest, for research suggests that cruciferous vegetables are not only an important source of nutrients, but perhaps a key to eliminating cancer as a lifethreatening disease. Cruciferous vegetables such as kale, cabbage, Brussels sprouts, and broccoli sprouts contain chemical components, such as sulforaphane (SFN) and indole-3carbinol (I3C), which have been revealed to be regulators of microRNAs (miRNAs) and inhibitors of histone deacetylases
\end{abstract}

This article is part of the Topical Collection on Epigenetics and Phytochemicals

K. J. Royston · T. O. Tollefsbol

Department of Biology, University of Alabama at Birmingham,

1300 University Boulevard, Birmingham, AL 35294, USA

\section{K. J. Royston}

e-mail: Kendroy@uab.edu

T. O. Tollefsbol

Comprehensive Center for Healthy Aging, University of Alabama

Birmingham, 1530 3rd Avenue South, Birmingham, AL 35294, USA

\section{T. O. Tollefsbol}

Comprehensive Cancer Center, University of Alabama Birmingham, 1802 6th Avenue South, Birmingham, AL 35294, USA

\section{T. O. Tollefsbol}

Nutrition Obesity Research Center, University of Alabama

Birmingham, 1675 University Boulevard, Birmingham,

AL 35294, USA

T. O. Tollefsbol

Comprehensive Diabetes Center, University of Alabama

Birmingham, 1825 University Boulevard, Birmingham,

AL 35294, USA

\section{T. O. Tollefsbol $(\bowtie)$}

University of Alabama at Birmingham, 175 Campbell Hall,

1300 University Boulevard, Birmingham, AL 35294, USA

e-mail: trygve@uab.edu
(HDACs) and DNA methyltransferases (DNMTs). The misregulation and overexpression of these genes are responsible for the uncontrolled cellular proliferation and viability of various types of cancer cells. The field of epigenetics and its incorporation into modern medicinal investigation is an exponentially growing field of interest and it is becoming increasingly apparent that the incorporation of an epigenetic diet may in fact be the key to chemoprevention.

Keywords Sulforaphane · Indoles · Glucosinolates · Cruciferous · Vegetables · Cancer · Prevention . Chemopreventive diet $\cdot$ Epigenetics $\cdot$ Food $\cdot$ Broccoli . Cabbage $\cdot$ Isothiocyanates $\cdot$ Indole-3-carbinol $\cdot$ Medicine Heredity $\cdot$ HDAC $\cdot$ DNMT $\cdot$ miRNA $\cdot$ Nutrients $\cdot$ Apoptosis

\section{Introduction}

The field of epigenetics has rapidly expanded since the 1940's, especially with respect to cruciferous vegetables and chemoprevention. The answer to chemoprevention has perhaps been available to the masses in the form of healthy eating throughout the course of mankind's existence. This fast growing field of study - in which investigators are quickly approaching broader comprehension of many diseases that occur through epigenetic modifications - has grown in importance over the years. Epigenetics, or the study of hereditable changes (passed from cell to cell or generation to generation) that are not related to the changes in underlying DNA sequences [1], is regulated via many processes but perhaps most notably DNA methylation, modifications of the histones, and non-coding microRNA. DNA methyltransferases (DNMTs) and histone deacetylases (HDACs) play important roles in cellular proliferation and viability [2-4]. MicroRNAs (miRNAs) are important in the inhibition 
of translation and the degradation of mRNA [5]. miRNAs negatively regulate many genes, and their malfunction has been linked to various pathways of cancer [6]. One issue that arises with uncontrolled proliferation is the ability of cancer cells to use these epigenetic traits in the continued growth and spread of diseased cells. The incorporation of miRNA regulators and DNMT/HDAC inhibitors as a means to promote apoptosis and prevent uncontrolled cellular proliferation through dietary consumption has proven to be a promising field of study to improve current cancer remediation $[2,7 \bullet, 8 \bullet 9]$. The ingestion of indoles and isothiocyanates shows tremendous results on improving both hormone-based [9-11] and non-hormonebased chemotherapies, which is another reason the epigenetic diet, or the control of epigenetic modifiers through the consumption of dietary phytochemicals, is of extreme interest. Many studies suggest that cruciferous vegetables are not only an important source of nutrients but also important in the elimination of cancer as a life-threatening disease [7•, 12-14].

The idea that the consumption of an epigenetic diet can have life-altering effects is remarkable, and there are ongoing efforts to unravel the mysteries regarding the impact of glucosinolates, isothiocyanates, and indoles, which have been reported to lead to apoptosis and cell cycle arrest in carcinogenic cells [14-17]. Cruciferous vegetables (CV) such as kale, cabbage, Brussels sprouts, and broccoli sprouts contain chemical components including sulforaphane (SFN) and indole-3carbinol (I3C) which have been revealed to be potent inhibitors of HDACs and DNMTs $[2-4,9,18]$. The field of epigenetics and its incorporation into modern medicinal regimens appears to have a considerable potential in health maintenance in that the incorporation of an epigenetic diet may in fact be the key to the prevention of cancer and many other diseases regulated via epigenetic modifications to the histones. Additionally, some studies have shown SFN and I3C to have an effect on estrogen receptor (ER) in breast cancer cells $[10,19]$. These specific studies suggest that future research may lead to breakthroughs in understanding better means to treat breast cancer and enhance hormone-based therapies through the incorporation of broccoli and other cruciferous vegetables into the human diet.

\section{Cruciferous Vegetables (CV)}

Brassicaceae, or cruciferous vegetables, have chemical components that exhibit anti-inflammatory effects [20 $]$. These foods also drive the detoxification of certain carcinogenic enzymes and are toxic to many types of cancer cells [21]. The consumption of a typical serving of vegetables such as cabbage, broccoli, Brussels sprouts, and many others of cruciferin nature (Table 1) may significantly decrease and lessen the incidence of carcinogenic fatality [22]. In fact, evidence shows that individuals who consume a diet rich in $\mathrm{CV}$ have
Table 1 Concentrations of glucosinolates present in a typical serving of $\mathrm{CV}$

\begin{tabular}{llll}
\hline Common CV & $\begin{array}{l}\text { Approx. } \\
\text { amount (g) }\end{array}$ & Glucosinolates (mg) & References \\
\hline Brussels sprouts & 50 & 123 & {$[52]$} \\
Broccoli & 50 & 30.5 & {$[52]$} \\
Cabbage & 50 & 54.5 & {$[52]$} \\
Cauliflower & 50 & 31 & {$[52]$} \\
\hline
\end{tabular}

The amounts of glucosinolates in milligrams that are present in a typical serving of a few common cruciferous vegetable are summarized

lower risks of developing cancer [23]. As seen in Table 2, cruciferous vegetables contain chemical components referred to as glucosinolates which give rise to indoles, isothiocyanates, thiocyanates, and cyano-epithioalkanes via mastication as a result of the release of the enzyme myrosinase [24]. Thiocyanates are compounds found in great abundance in foods such as cassava and yams and are evidenced to be inversely associated with sickle cell anemia and hypertension, diseases prevalent in the African American community [25, 26]. In fact, it has been reported that individuals who consume diets rich in yams and cassava are less likely to suffer from sickle cell anemia due to the high availability of thiocyanates and the anti-sickling effects of these foods [27]. Cyano-epithioalkanes are components that can be found in rapeseeds in which canola oil is derived [28]. Canola is used as common cooking oil and is beneficial in lowering cholesterol levels [29]. Of the glucosinolates listed in Table 2, indoles and isothiocyanates reveal promising results with respect to cancer prevention. These glucosinolates are important for they are precursors to compounds such as sulforaphane and indole-3-carbinol.

\section{Isothiocyanates: Sulforaphane}

As aforementioned, isothiocyanates are derived from glucosinolates and their exposure to myrosinase (Fig. 1). Phenethyl

Table 2 Glucosinolates and their subcategories

\begin{tabular}{lll}
\hline Glucosinolates & Sub-Categories & References \\
\hline Isothiocyanates & $\begin{array}{l}\text { Sulforaphane, erucin, phenethyl } \\
\text { isothiocyanate } \\
\text { Indole-3-carbinol }\end{array}$ & {$[53]$} \\
Nitriles & $\begin{array}{l}\text { Propionitrile, succinonitrile, crotonitrile, } \\
\text { cyanopyrazine }\end{array}$ & {$[55]$} \\
Thiocyanates & $\begin{array}{l}\text { Cavernothiocyanate, } \\
\text { 2-thiocyanatoneopupu-keanane, } \\
\text { 4-thiocyanato-9-cadinene }\end{array}$ & \\
& & {$[56]$} \\
\hline
\end{tabular}

Isothiocyanates, indoles, nitriles, and thiocyanates give rise to a varied array of compounds. This table lists examples of the compounds in which glucosinolates are the precursors 
Fig. 1 Steps to anti-carcinogen compounds: This flow chart is a simple depiction of how compounds such as SFN and I3C are formed. Once the myrosinase enzyme is released via mastication or bacterial fermentation of cruciferous vegetables, glucosinolates are formed which give rise to isothiocyanates, indoles, and other compounds

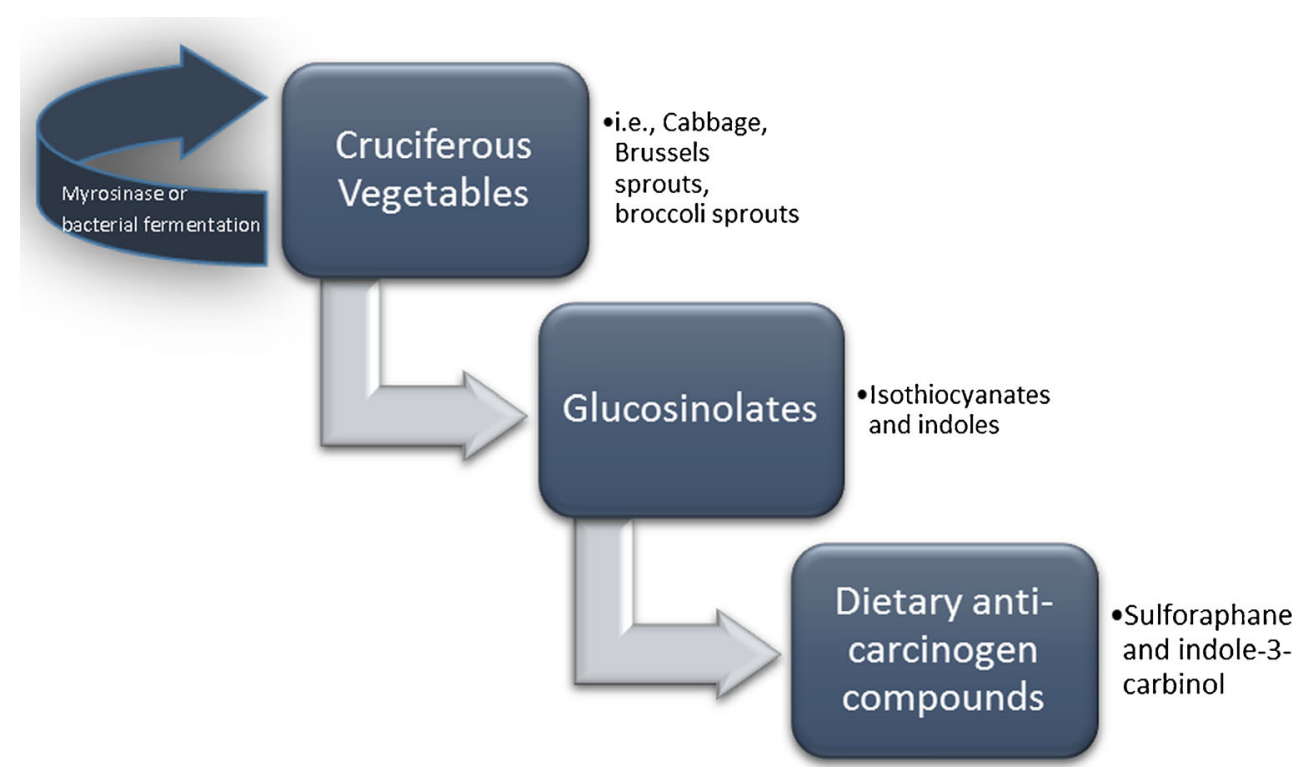

isothiocyanate (PEITC) and sulforaphane (SFN) are two dietary isothiocyanates studied in abundance. PEITC modulates miRNA expression and protects the lungs from environmental smoke-induced miRNA alterations [30]. This is important because miRNA mutations are one mechanism by which cancer can develop. The isothiocyanate SFN is found in abundance in cruciferous vegetables, more specifically, broccoli sprouts are the most prevalent and common source for this compound [3, $8 \bullet, 9,31]$. SFN became the subject of considerable interest as a result of the development, by Prochaska and associates in the late 1980's, of a cell-culture system that detected the induction of anti-carcinogenic phase two enzymes. Upon analyzing a vast array of extracts from fruits and vegetables, Prochaska discovered that the broccoli extract had a significant amount of impact on phase 2 enzyme induction [32,33]. According to Zhang and Tang, they were successful in isolating the liquid component that was responsible for more than $80 \%$ of inducer activity, thus began the incorporation of SFN as an anticarcinogen in the vast array of chemoprevention investigations. SFN has several benefits and may be an effective therapy for the reduction of tumor size as well as for combating multiple pathways of cancer.

Various studies reveal SFN to be an effective inhibitor of HDACs and an inducer of apoptosis through multiple pathways in different cancer types as well as a repressor of human telomerase reverse transcriptase ( $h T E R T)$ gene and its protein product in breast cancer cells [34]. As an HDAC inhibitor, SFN destabilizes androgen receptor, the main signaling pathway regulated by the HDAC6 enzyme, in prostate cancer cells [35]. It is important to note that the use of the SFN HDAC inhibitor for chemoprevention renders very little effect on non-transformed cells [16]. The introduction of SFN causes the activation of caspase-3, eight and polymerase as a result of the incorporation of the Fas ligand in the breast cancer cell line
MDA-MB 231; however, in the breast cancer cell lines MDAMB-468, MCF-7, and T47D, it is the activation of caspase-3, caspase- 9 , polymerase cleavage, decreased expression of Bcl2 , and the release of cytochrome- $\mathrm{C}$ into the cytosol that are responsible for the initiation of apoptosis [36]. Recent findings, in addition to HDAC inhibition by SFN, have indicated that SFN is an inhibitor of DNMT expression [34, 37]. Therefore, the epigenetic impact likely extends beyond changes in the chromatin of key tumor-related genes and also affects DNA methylation. DNMTs, which are prominent in most cancers, enhance and increase the methylation of DNA. Evidence from our laboratory suggests that SFN serves as a downregulator of DNMT and is involved in the demethylation of the hTERT control region in the process of anti-carcinogenesis [34, 38••, $39,40]$. SFN also suppresses polycomb group protein $(\mathrm{PcG})$ levels in skin cancer cells which are instrumental in the methylation of histones and suppression of gene expression [41]. This isothiocyanate has also been shown to regulate miRNAs which have major roles in the regulation of genes that manipulate chemoresistance. In fact, miRNA knockdown results in not only increased apoptosis of cancer cells and sensitivity to certain cancer therapeutics but also the restoration of ER $\alpha$ in $\mathrm{ER} \alpha$-negative cell lines which has implications of improving current chemotherapies and making them more effective through the activation of estrogen hormone receptors [6, 42]. Furthermore, SFN is effective in combination with other chemopreventive compounds such as epigallocatechin gallate [38••], a green tea polyphenol which functions as an enhancement of SFN, as well as in combination with other chemotherapeutic agents making those therapies more effective [39, 40, 43]. Other sources indicate that the incorporation of SFN into the human diet may in fact help to prevent and lessen the incidence of the acquisition of breast, prostate, colon, and many other cancers $[2,9,44]$. 


\section{Indoles: Indole-3-carbinol}

There is more than just one mechanism by which CVs negatively impact cancer progression. Indoles, another derivative of glucosinolates, are found in abundance in CVs, and indole3 -carbinol (I3C) is showing promising evidence as a cancer preventive therapeutic. I3C has been reported to be an inducer of estradiol 2-hydroxylation which influences estrogen activity and may be one reason why it has shown positive results as a cancer therapy [45]. Further, I3C may serve as a natural antioxidant and as such is likely to intervene in cancer progression [46]. Estrogen is instrumental in the increase of tumor size in breast cancer patients, and $\mathrm{I} 3 \mathrm{C}$ is extremely significant in this regard for it serves as a negative regulator of estrogen $[10,15]$. A separate study also reveals I3C to be an inhibitor of mammary gland tumorigenesis which may be due to the increase of 2-hydroxyestrone and the decrease of $16 \alpha$ hydroxyestrone [47]. This is remarkable for multiple studies reveal other byproducts of cruciferous vegetables, such as SFN, to have similar effects [48]. I3C also facilitates protection from cellular damage caused by free radicals [46], and it is instrumental in defending against hormonal imbalances rendering it ideal as a component of prostate and breast cancer prevention in certain cases [11, 15, 49-51].

p21 and p27 are associated with cell cycle progression and $\mathrm{Bax} / \mathrm{BCI} 2$ is associated with apoptosis. I3C has several effects on the expression of many genes via nuclear regulation of transcription factors which include the upregulation of $\mathrm{p} 21$, p27, Bax/BCI2, CYP1A, BRCA, GADD153 and the downregulation of the food carcinogen, 2-amino-1-methyl-6phenylimidazo[4,5-b]pyridine (PhIP) [11, 15, 48-50]. PhIP is a heterocyclic amine resultant from the preparation of meats at high temperatures $[48,49]$. This has a significance because BRCA and GADD153 are associated with carcinogen bioactivation and PhIP-DNA is associated with DNA repair $[49,50]$. Additionally, the downregulation of miRNA-21, a miRNA that is typically overexpressed in chemoresistant pancreatic cancer cells, is induced by I3C. This downregulation is important in the increased sensitivity and cytotoxicity of pancreatic cancer cells [52].

\section{Conclusion}

Many studies have contributed to the incorporation of dietary agents as forms of cancer remediation. Cruciferous vegetables are enriched with several chemical components that have tremendous negative effects on multiple pathways of cancer cells due to their anti-proliferative and anti-tumorigenic properties. The consumption of these vegetables is beneficial in the sense that they are precursors to glucosinolates which give rise to isothiocyanates such as sulforaphane and indoles such as indole-3-carbinol. Most cancers are characterized by the overexpression of HDAC and DNMT and the mis-expression of miRNAs. Both I3C and SFN are inhibitors and regulators of these processes and the incorporation of these compounds causes cancerous cell lines to take on a healthier and more normalized appearance. In addition, significant decreases in uncontrolled cell growth as well as increases in programed cell death are noticed with the incorporation of SFN and I3C. Many studies reveal that cruciferous vegetables are key instruments in advancing progress toward the prevention of cancer. Future studies will undoubtedly be directed toward further deciding the epigenetic events impacted by the bioactive components of cruciferous vegetables and their significance with respect to not only cancer prevention but also many other biological processes.

Acknowledgments This work was supported in part by grants from the National Science Foundation Bridge to Doctorate Fellowship Program, the National Cancer Institute (RO1 CA178441), and the American Association for Cancer Research. A special thanks goes to all of the members of the Tollefsbol laboratory at the University of Alabama at Birmingham.

\section{Compliance with Ethics Guidelines}

Conflict of Interest Kendra J Royston and Trygve O. Tollefsbol declare that they have no conflict of interest.

Human and Animal Rights and Informed Consent This article does not contain any studies with human or animal subjects performed by any of the authors.

\section{References}

Papers of particular interest, published recently, have been highlighted as:

- Of importance

•. Of major importance

1. Chekhun VF. Cancer epigenetics. Exp Oncol. 2008;30(3):170.

2. Ho E, Clarke JD, Dashwood RH. Dietary sulforaphane, a histone deacetylase inhibitor for cancer prevention. J Nutr. 2009;139(12): 2393-6.

3. Clarke JD et al. Differential effects of sulforaphane on histone deacetylases, cell cycle arrest and apoptosis in normal prostate cells versus hyperplastic and cancerous prostate cells. Mol Nutr Food Res. 2011;55(7):999-1009.

4. Fan $\mathrm{H}$ et al. Sulforaphane causes a major epigenetic repression of myostatin in porcine satellite cells. Epigenetics. 2012;7(12): 1379-90.

5. Kutty RK et al. MicroRNA expression in human retinal pigment epithelial (ARPE-19) cells: increased expression of microRNA-9 by N-(4-hydroxyphenyl)retinamide. Mol Vis. 2010;16:1475-86.

6. Esquela-Kerscher A, Slack FJ. Oncomirs - microRNAs with a role in cancer. Nat Rev Cancer. 2006;6(4):259-69.

7. Suppipat K et al. Sulforaphane induces cell cycle arrest and apoptosis in acute lymphoblastic leukemia cells. PLoS One. 2012;7(12): e51251. SFN is important in the regulation of several biological 
mechanisms that help prevent the metastasis of cancer. This source is of interest for it reveals that the proliferation of lymphoblastic leukemia cells is adversely affected by the incorporation of SFN suggesting that multiple cancer types are regulated by similar pathways which may allow SFN to serve as a broad therapy.

8. Sakao K, Singh SV. D,L-sulforaphane-induced apoptosis in human breast cancer cells is regulated by the adapter protein p66Shc. J Cell Biochem. 2012;113(2):599-610. SFN induces apoptosis of more than one cancer type. This source reveals SFN to be affective in the promotion of said apoptosis through the regulation of p66Shc. This information facilitates understanding of the mechanisms by which SFN is able to hinder the growth and spread of cancerous cells.

9. Myzak MC et al. A novel mechanism of chemoprotection by sulforaphane: inhibition of histone deacetylase. Cancer Res. 2004;64(16): 5767-74.

10. Yuan F et al. Anti-estrogenic activities of indole-3-carbinol in cervical cells: implication for prevention of cervical cancer. Anticancer Res. 1999;19(3A):1673-80.

11. Auborn KJ et al. Indole-3-carbinol is a negative regulator of estrogen. J Nutr. 2003;133(7 Suppl):2470S-5S.

12. Lampe JW, Peterson S. Brassica, biotransformation and cancer risk: genetic polymorphisms alter the preventive effects of cruciferous vegetables. J Nutr. 2002;132(10):2991-4.

13. Shapiro TA et al. Human metabolism and excretion of cancer chemoprotective glucosinolates and isothiocyanates of cruciferous vegetables. Cancer Epidemiol Biomarkers Prev. 1998;7(12): 1091-100.

14. Shankar S, Srivastava R. SpringerLink (Online service), nutrition, diet and cancer. Dordrecht: Springer; 2012. p. 1. online resource (xv, $627 \mathrm{p}$.).

15. Meng $\mathrm{Q}$ et al. Indole-3-carbinol is a negative regulator of estrogen receptor-alpha signaling in human tumor cells. J Nutr. 2000;130(12): 2927-31.

16. Higdon JV et al. Cruciferous vegetables and human cancer risk: epidemiologic evidence and mechanistic basis. Pharmacol Res. 2007;55(3):224-36.

17. Kojima T, Tanaka T, Mori H. Chemoprevention of spontaneous endometrial cancer in female Donryu rats by dietary indole-3-carbinol. Cancer Res. 1994;54(6):1446-9.

18. Lee JH et al. Dietary phytochemicals and cancer prevention: Nrf2 signaling, epigenetics, and cell death mechanisms in blocking cancer initiation and progression. Pharmacol Ther. 2013;137(2): 153-71.

19. Li Y et al. Epigenetic reactivation of estrogen receptor-alpha (ERalpha) by genistein enhances hormonal therapy sensitivity in ERalpha-negative breast cancer. Mol Cancer. 2013;12:9.

20. Wagner AE, Terschluesen AM, Rimbach G. Health promoting effects of brassica-derived phytochemicals: from chemopreventive and anti-inflammatory activities to epigenetic regulation. Oxid Med Cell Longev. 2013;2013:964539. The phytochemicals in cruciferous vegetables are reported have chemopreventive properties as well as anti-inflammatory effects. This further supports the evidence that cruciferous vegetables adversely regulate chemo-progression.

21. Rose P, Ong CN, Whiteman M. Protective effects of Asian green vegetables against oxidant induced cytotoxicity. World $\mathrm{J}$ Gastroenterol. 2005;11(48):7607-14.

22. Arikawa AY, Gallaher DD. Cruciferous vegetables reduce morphological markers of colon cancer risk in dimethylhydrazine-treated rats. J Nutr. 2008;138(3):526-32.

23. Tang $\mathrm{L}$ et al. Consumption of raw cruciferous vegetables is inversely associated with bladder cancer risk. Cancer Epidemiol Biomarkers Prev. 2008;17(4):938-44.

24. Kelleher MO et al. 1-Cyano-2,3-epithiopropane is a novel plantderived chemopreventive agent which induces cytoprotective genes that afford resistance against the genotoxic alpha, beta-unsaturated aldehyde acrolein. Carcinogenesis. 2009;30(10):1754-62.

25. Hines Jr EA. The thiocyanates in the treatment of hypertensive disease. Med Clin North Am. 1946;30(4):869-77.

26. THIOCYANATES in hypertension. Ann West Med Surg. 1947;1(4): 173-6.

27. Agbai O. Anti-sickling effect of dietary thiocyanate in prophylactic control of sickle cell anemia. J Natl Med Assoc. 1986;78(11): 1053-6.

28. Wathelet JP et al. Measurement of glucosinolates in rapeseeds. Nat Toxins. 1995;3(4):299-304. discussion 317.

29. Lin $\mathrm{L}$ et al. Evidence of health benefits of canola oil. Nutr Rev. 2013;71(6):370-85.

30. Izzotti A et al. Modulation of microRNA expression by budesonide, phenethyl isothiocyanate and cigarette smoke in mouse liver and lung. Carcinogenesis. 2010;31(5):894-901.

31. Clarke JD et al. Comparison of isothiocyanate metabolite levels and histone deacetylase activity in human subjects consuming broccoli sprouts or broccoli supplement. J Agric Food Chem. 2011;59(20): 10955-63.

32. Prochaska HJ, Santamaria AB. Direct measurement of NAD $(\mathrm{P}) \mathrm{H}$ : quinone reductase from cells cultured in microtiter wells: a screening assay for anticarcinogenic enzyme inducers. Anal Biochem. 1988;169(2):328-36.

33. Zhang Y, Tang L. Discovery and development of sulforaphane as a cancer chemopreventive phytochemical. Acta Pharmacol Sin. 2007;28(9):1343-54

34. Meeran SM, Patel SN, Tollefsbol TO. Sulforaphane causes epigenetic repression of hTERT expression in human breast cancer cell lines. PLoS One. 2010;5(7):e11457.

35. Gibbs A et al. Sulforaphane destabilizes the androgen receptor in prostate cancer cells by inactivating histone deacetylase 6 . Proc Natl Acad Sci U S A. 2009;106(39):16663-8.

36. Pledgie-Tracy A, Sobolewski MD, Davidson NE. Sulforaphane induces cell type-specific apoptosis in human breast cancer cell lines. Mol Cancer Ther. 2007;6(3):1013-21.

37. Su ZY et al. Requirement and epigenetics reprogramming of Nrf2 in suppression of tumor promoter TPA-induced mouse skin cell transformation by sulforaphane. Cancer Prev Res (Phila). 2014;7(3): 319-29.

38.• Meeran SM et al. Bioactive dietary supplements reactivate ER expression in ER-negative breast cancer cells by active chromatin modifications. PLoS One. 2012;7(5):e37748. Some dietary compounds have the ability to activate estrogen receptor expression in breast cancer cells that are negative for the expression estrogen receptor. This assists in the creation of a more uniform cancer type in order to make multiple cancers more receptive to one treatment type.

39. Chen $\mathrm{H}$ et al. Enhancement of cisplatin-mediated apoptosis in ovarian cancer cells through potentiating G2/M arrest and p21 upregulation by combinatorial epigallocatechin gallate and sulforaphane. J Oncol. 2013;2013:872957.

40. Chen $\mathrm{H}$ et al. Epigallocatechin gallate and sulforaphane combination treatment induce apoptosis in paclitaxel-resistant ovarian cancer cells through hTERT and Bcl-2 down-regulation. Exp Cell Res. 2013;319(5):697-706.

41. Balasubramanian S, Chew YC, Eckert RL. Sulforaphane suppresses polycomb group protein level via a proteasome-dependent mechanism in skin cancer cells. Mol Pharmacol. 2011;80(5):870-8.

42. Kala R et al. MicroRNAs: an emerging science in cancer epigenetics. J Clin Bioinforma. 2013;3(1):6.

43. Chen $\mathrm{H}$ and University of Alabama at Birmingham. Graduate School. Targeting ovarian cancer through epigallocatechin gallate and sulforaphane combinatorial treatment. p. 1 online resource (xv, 172 pages). 
44. Wiczk A et al. Sulforaphane, a cruciferous vegetable-derived isothiocyanate, inhibits protein synthesis in human prostate cancer cells. Biochim Biophys Acta. 2012;1823(8):1295-305.

45. Zhu BT, Conney AH. Is 2-methoxyestradiol an endogenous estrogen metabolite that inhibits mammary carcinogenesis? Cancer Res. 1998;58(11):2269-77.

46. Shertzer HG, Berger ML, Tabor MW. Intervention in free radical mediated hepatotoxicity and lipid peroxidation by indole-3-carbinol. Biochem Pharmacol. 1988;37(2):333-8.

47. Jin $\mathrm{L}$ et al. Indole-3-carbinol prevents cervical cancer in human papilloma virus type 16 (HPV16) transgenic mice. Cancer Res. 1999;59(16):3991-7.

48. Hu R et al. Cancer chemoprevention of intestinal polyposis in ApcMin/+ mice by sulforaphane, a natural product derived from cruciferous vegetable. Carcinogenesis. 2006;27(10):2038-46.

49. Wang TT et al. Estrogen receptor alpha as a target for indole-3carbinol. J Nutr Biochem. 2006;17(10):659-64.

50. Kim YS, Milner JA. Targets for indole-3-carbinol in cancer prevention. J Nutr Biochem. 2005;16(2):65-73.
51. Chinni SR et al. Indole-3-carbinol (I3C) induced cell growth inhibition, G1 cell cycle arrest and apoptosis in prostate cancer cells. Oncogene. 2001;20(23):2927-36.

52. Paik WH et al. Chemosensitivity induced by down-regulation of microRNA-21 in gemcitabine-resistant pancreatic cancer cells by indole-3-carbinol. Anticancer Res. 2013;33(4):1473-81.

53. McNaughton SA, Marks GC. Development of a food composition database for the estimation of dietary intakes of glucosinolates, the biologically active constituents of cruciferous vegetables. Br J Nutr. 2003;90(3):687-97.

54. Konsue N, Ioannides C. Phenethyl isocyanate is not the metabolite of phenethyl isothiocyanate responsible for mechanism-based inhibition of cytochrome P450. Arch Toxicol. 2010;84(10):751-9.

55. Watson RR, Preedy VR. Bioactive foods and extracts [electronic resource]: cancer treatment and prevention. Bocan: CRC Press; 2011. 1 online resource (xx, 643 p.).

56. Vesela $\mathrm{AB}$ et al. Biotransformation of benzonitrile herbicides via the nitrile hydratase-amidase pathway in rhodococci. J Ind Microbiol Biotechnol. 2012;39(12):1811-9. 